Estudios Románicos, Volumen 30, 2021, pp. 261-272

ISSN: 0210-4911

eISSN: 1989-614X

DOI: https://doi.org/10.6018/ER.471911

\title{
EL ARTE ENTREMESIL DE JERÓNIMO DE CÁNCER Y VELASCO
}

(The theatrical art of Jerónimo de Cáncer y Velasco)

\author{
Juan Carlos González Maya* \\ Universidad de las Islas Baleares
}

\begin{abstract}
Jerónimo de Cáncer y Velasco, a comedian from the first half of the seventeenth century, is one those witty geniuses that in monographs, anthologies or short theatrical treatises shine for their abilities, though on the contrary he has had little fortune in modern publications. For this reason, he has only reached the public partially or has been insufficiently published. The present article tries, precisely for this reason, to bring to light his work in theatre interlude performances by taking a critical look at his most unexplored or unpublished works, starting with the publication of his first anthology of theatrical pieces.
\end{abstract}

Keywords: Jerónimo de Cáncer; interludes; critical theatre editions.

Resumen: don Jerónimo de Cáncer y Velasco, comediante de la primera mitad del siglo XVII, es uno de esos ingenios que en las monografías, antologías o tratados de teatro breve siempre se destaca por su ingenio cómico. En cambio, ha sufrido escasa fortuna en las prensas modernas. Motivo por el cual nos ha llegado solo parcial e insuficientemente editado. En el presente artículo se intenta, precisamente por ello, un acercamiento a su arte entremesil a través de una mirada crítica a sus piezas más recónditas o inéditas en honor a sus merecimientos, a partir de la publicación de la primera antología de su teatro breve.

Palabras clave: Jerónimo de Cáncer; entremeses; ediciones críticas de teatro.

\section{Justificación}

Decía la especialista Hannah E. Bergman sobre la popularidad de Cáncer y Velasco en su Ramillete de entremeses y bailes: «se cantaban sus jácaras en todas partes, y su nombre, acoplado con el de Benavente, venía a ser sinónimo de entremés. Décadas después de su

\footnotetext{
* Dirección para correspondencia: Torcuato Luca de Tena, 9, 5A, 07005, Palma Mallorca. (j-c.gonzalez@uib.es).
} 
muerte se le cita todavía como modelo de agudeza y donaire» (1970: 279). Se sabe que su fama se extendió a lo largo de todo su siglo y que penetró en el xvIII, cuando el Diccionario de Autoridades incluyó 188 citas suyas; y, todavía en 1874, la Academia Española lo nombró autoridad de la lengua por vía del ejemplo en su Catálogo de los escritores que pueden servir de autoridad en el uso de los vocablos y de las frases de la lengua castellana (1874: 18). En la misma medida que otros contemporáneos suyos como Antonio Hurtado de Mendoza, Luis Vélez de Guevara o Antonio de Solís ${ }^{1}$, fue personaje muy vinculado al círculo intelectual de la corte de Felipe $\mathrm{IV}^{2}$, con trayectoria en los escenarios palaciegos, como él mismo se encarga de recordar con desinhibición en su poesía: «Al Rey Nuestro Señor, pidiéndole una ayuda de costa, habiendo representado el Poeta en la Comedia que hicieron los criados de Su Majestad»², dando rienda suelta así a su bufonería más descarada.

¿Qué ha podido ocurrir entonces para que su nombre pasara del éxito al ostracismo y mereciera tan escasa atención filológica? Cuesta hoy día hacerse una idea cabal de la fama y el reconocimiento que pudo tener entre sus contemporáneos, y que se tenga que convertir en lugar común su olvido. Descartada la ausencia de calidad, a pesar de los juicios parcos de la crítica, es posible que pesara la concepción de "teatro menor", en su aspecto más peyorativo, que durante tanto tiempo gozó el entremés, poco menos que un entretenimiento al margen de la literatura. Solo a partir del rescate de la obra del Lope de Vega del entremés, Luis Quiñones de Benavente, empezó a cambiar esta sensibilidad estética, y, ya con juicio más ecuánime, se han ido lentamente ponderando estas obras con estudios y ediciones de sus cultivadores, lejos de los clichés repetidos. Empezando en el ya lejano 1911 con la fundacional Colección de entremeses, loas, bailes, jácaras y mojigangas de don Emilio Cotarelo y Mori y continuando en los años 60 con Eugenio Asensio, la citada Hannah E. Bergman o, más recientemente, Abraham Madroñal, Celsa Carmen García Valdés, Catalina Buezo, $\mathbf{M}^{\mathrm{a}}$ Luisa Lobato, Ignacio Arellano o Javier Huerta Calvo, por citar solo una pequeña muestra de especialistas. Hasta que en 2012 apareció la primera edición moderna de una de las colecciones de teatro breve más célebres del siglo xvII, por la categoría de sus integrantes, los Entremeses Nuevos para honesta recreación, de 1643.

Aunque en los últimos años Cáncer ha dejado de ser un desconocido, en el ámbito congresual su aparición ha sido poco menos que testimonial. Algunas citas aisladas, pero ninguna ponencia o comunicación a su nombre ${ }^{4}$. En 2005 Rus Solera publicó las Obras varias (1651), compendio de gran parte de sus poemas más su vejamen satírico; y dos años más tarde salió al mercado su poesía completa en edición crítica sobre mi tesis doctoral leída en 2000.

En cuanto a la suerte de su teatro breve, su difusión constituía todavía un caramelo que estaba aguardando más de 300 años, en espera de una necesaria revisión y pues-

\footnotetext{
$1 \quad$ Este último, según Farré Vidal 2016: 13, dramaturgo oficial de palacio en 1651.

2 El más completo estudio hasta la fecha, desde el punto de vista artístico y literario, es el de Julio Vélez Sainz (2017), El rey planeta.

3 Poesía completa, $\mathrm{n}^{\circ} 5$.

4 Si descontamos una comunicación que presenté sobre su poesía satírico-burlesca en el congreso de la AISO de Cambridge (2005).
} 
ta al día que arrojara luz sobre esa paradoja del éxito y del olvido, convertida ya en cansino tópico. En este orden de cosas, una primera cuestión surgía de la necesidad de establecer un corpus definitivo de su obra completa y su transmisión, como primer marco de referencia para futuros acercamientos. Tarea que me fue encomendada para el Diccionario filológico del Siglo de Oro, de Castalia (2010). Dos años antes, gracias a la iniciativa de Javier Huerta Calvo y su Historia del teatro breve en España, se hizo realidad el primer estudio aproximativo de sus entremeses, debido al profesor italiano Pietro Taravacci. Aunque no se daba con la técnica compositiva, al menos sí se ofrecía un acercamiento más real a sus títulos más significativos. Cáncer empezaba a salir de la penumbra.

Ahora bien, el círculo no se podía cerrar hasta que no apareciera una edición crítica anotada de su producción breve, porque si bien algunas piezas suyas habían circulado a partir de la década de los 60 del siglo pasado en antologías varias, todavía estas no se habían reunido en un único volumen. Cabe citar, en esta dirección, la pionera Felicidad Buendía (1965), la mencionada Bergman (1970), pero también García Valdés (1985), Huerta Calvo (1985 y 1999), Arellano (2005) o Sáez Raposo (2005)5, quienes sí supieron incluir su nombre entre lo más granado del género. La mirada crítica volvía a depositarse sobre su persona, y eso suponía no solo un cierto reconocimiento formal sino el inicio de una tradición científica en disposición de revisar sus intermedios cómicos, aunque todavía no de estudiarlos.

Hasta que en diciembre de 2019 vio la luz la primera entrega de su teatro breve titulada Doce entremeses nuevos. Finalizaba así una travesía de más de 300 años. Representaba el primer intento de reunir un corpus significativo de este tipo de piezas, con el fin de ofrecer una edición moderna, filológica, y con estudio crítico introductorio, sobre unas obras que se representaron en su momento, pero que habían quedado sepultadas o, incluso, no llegaron a la imprenta y permanecieron manuscritas; por tanto, desconocidas pero no inéditas, salvo en algún caso. Los entremeses en cuestión fueron: Este lo paga, El francés, El gigante, Los golosos de Benavente, Juan Rana mujer, Juan Ranilla, Las lenguas, El libro de qué quieres, boca, La mariona, La regañona y fiesta de toros, El sí y El tamborilero.

\section{La transmisión}

La transmisión de este tipo de teatro, harto accidentada a causa de los diversos avatares padecidos, comparte conflictos con los de su hermana mayor, la comedia. A saber: la falta de autógrafos, las atribuciones y las dificultades para establecer un texto fiable. Cuestiones siempre complicadas, en parte por la misma génesis de la fiesta teatral, más bien pensada para el regocijo del espectador que no para su perduración escrita. $\mathrm{Su}$ función lúdica, sin embargo, no tiene que confundirse con su falta de valor literario. No obstante, la circunstancia de la inmediatez del espectáculo y el proceso de venta de los originales incidió en la deficiente transmisión y en la ausencia de autógrafos. Además,

\footnotetext{
$5 \quad$ Ver en la Bibliografía las entradas correspondientes.
} 
las impresiones tardías escapaban al control de sus creadores, iniciando un camino pleno de incertidumbres, circunstancia de lo más habitual; y Cáncer, a diferencia de Quiñones de Benavente, nunca se interesó en acometer lo mismo que concibió para su poesía, la compilación de su teatro breve; circunstancia, por otra parte, habitual en el resto de compañeros de generación.

Todas las piezas presentadas se redactaron durante su periodo de madurez, entre finales de los años 30 y primeros 50, etapa de consolidación del género y de su mayor éxito. Sin embargo, ha resultado complicado proponer una datación concreta para las redacciones, bien por la falta de referencias internas o porque las fuentes consultadas no arrojaron éxito. Salvo en el caso del Entremés de este lo paga, donde se alude a la comedia de Calderón Las manos blancas no ofenden, representada en 1640 (Valbuena Prat 1937: 1079).

El de las atribuciones y cambios de títulos es otro asunto espinoso. En este repertorio su nombre se asocia al de los ilustres Quiñones de Benavente o Calderón de la Barca, o a los más desconocidos Pedro Rosete Niño y Sebastián Rodríguez de Villaviciosa. Salvo el toledano, amigos o conocidos suyos.

Aún aplicando los instrumentos de la crítica textual, el deslinde de atribuciones siempre arroja dudas. Pongamos por caso el Entremés de las lenguas, atribuido también a Calderón. El primer impreso con Cáncer al frente (Floresta de entremeses 1691) y los atribuidos al madrileño reproducen el mismo texto, con diferencias mínimas, repitiendo incluso erratas. Los manuscritos, en cambio, son más desiguales. A favor de Calderón juega su afición por las refundiciones y el hecho de que este acompañara a un auto sacramental suyo representado en 1674. Aunque la trama es parecida, el desarrollo es diferente y se reduce el número de personajes. A favor de Cáncer, la recreación de un personaje distintivo de su teatro breve, el italiano, que habla en una jerga macarrónica con términos que se repiten en otras obras suyas. El repertorio de frases hechas, refranes o bailes tan comunes a su poesía y teatro, también intervienen a su favor. Todo apunta a un entremés redactado por don Jerónimo, impreso tardíamente, de donde creció una mojiganga y otro entremés.

\section{Morfología e intertextualidad}

Uno de los puntos fuertes del Cáncer entremesista es el diálogo intertextual con sus fuentes. Donde mejor se observa este espejo metaliterario es en sus comedias burlescas, con parodia de mitos tan populares como el Cid o los infantes de Lara (a medias con Juan Vélez de Guevara). En los interludios actúan como hipotextos composiciones que pudieran apelar fácilmente al vulgo, como los casos del convidado de piedra en versión ridícula (Entremés de Juan Ranilla) o el famoso Escarramán de las jácaras (Entremés del libro de qué quieres, boca).

Otro tipo de vinculaciones es el de las reescrituras, refundiciones y repetición de fórmulas. Por esta vía se emparentan Los gigantes o El francés de Cáncer con Los gigantones o Los condes fingidos de Quiñones de Benavente, respectivamente; los mariones de Quevedo o Quiñones con Los putos o con Juan Ranilla; o los enfrentamientos de 
alcaldes, de tradición cervantina, con los de Juan Rana o Juan Ranilla. Las personificaciones de las figuras del refranero de Los refranes del viejo celoso, de autoría controvertida (Madroñal 2013: 155-177), pudieron inspirar el mismo desfile de La mariona, sustituyendo refranes por bailes.

Los materiales de origen folclórico representan una fuente inagotable de recursos con vasos comunicantes continuos que saltan de un lado a otro sin parar. Las paremias, canciones, cuentos, aún sometidos a un proceso de manipulación o depuración, son materiales de fácil acomodo para los espectáculos entremesiles y marcas que inciden en su nexo con el espectador. Recurso o fórmula dramática no potestativa del género breve, como bien se puede comprobar en el teatro lopesco y el de otros dramaturgos, sobre todo en el habla de los graciosos (González Cañal 2013: 862).

Estos ingredientes pueden infiltrarse en algún pasaje narrativo como un recurso más en la voz de algún personaje o bien dar lugar al diseño argumental, operando así sobre todo el conjunto. Baste citar como muestra el cuento popular picaresco de «Los cuatro estudiantes», donde unos tunantes se reúnen para conseguir comer gratis, en el Entremés de este lo paga, cuyos precedentes se pueden rastrear en el Patrañuelo de Timoneda (patraña 18) o en los italianos Arienti y Morlini (Espinosa 2009: 689); o el de la comida y el embeleco al simple del Entremés del libro de qué quieres, boca, popularizado por Lope de Rueda en sus pasos.

Hay más ejemplos de esta técnica. En la quinta década del siglo XvII, el jaque Escarramán, conocido personaje del hampa, ya había circulado por canciones, jácaras, o por las tablas desde que Quevedo lo popularizara. Pero Cáncer centra su interés en la transgresión cómica como juego metateatral. «Ya está metido en la trena tu querido Escarramán» (El libro de qué quieres, boca) sirve como letra de baile entre unas raposas y un alcalde incauto. En Este lo paga, «Las blancas manos nos agravian y estas lo son en extremo» se puede reconocer un guiño a su colaborador Calderón, con quien escribió dos comedias y quien le corresponde con palabras elogiosas en la aprobación de sus Obras varias (1651).

No hay entremés que no contenga algún refrán, proverbio, frase hecha y demás latiguillos en manos de cualquier personaje, bien textualmente o manipulado. Su uso es tan persistente que su estudio excede los límites de estas líneas. Baste mencionar las licencias que se permite con sus ocurrencias haciéndolas pasar como refranes. Tal es el caso de esta parodia del convidado de piedra: «Amigo, esto / no es comer sino probar / si es el refrán verdadero / de que cualquiera pastel / lo puede comer un muerto» (Juan Ranilla), refrán, si existe, no localizado; o en esta otra situación cuando al alcalde Rana, transformado en mujer, su esposa le saca una rueca y este contesta «esto es andar el uso sin pollera», que parece remitirnos a la paremiología, pero que en realidad no es más que una muestra más de su arraigado conceptismo verbal.

Los títulos de las obras también pueden ser recreación escénica del contenido de estas formulillas. Así, «Regalar a uno a qué quieres boca» (Covarrubias) da lugar al Entremés de qué quieres, boca; o «Mi marido es tamborilero, Dios me lo ha dado y así me lo quiero» al Entremés del tamborilero. Pero ese vínculo con el público se estrecha aún más si de lo que se trata es de escenificar una de las diversiones más populares de 
la época, el baile. El Entremés de la mariona es la personificación, a través de la protagonista del mismo nombre, una presa de la que anda enamorado el alcalde de la villa, de una famosa danza. Uno de los bailes lascivos que el Diablo Cojuelo se ufanaba de haber traído al mundo y que popularizó Luis Vélez de Guevara.

Con los materiales literarios y las canciones populares sucede otro tanto. Cáncer, gran conocedor de sus contemporáneos, no duda en recordar a Góngora con sus romances amorosos en clave humorística ( «iAy, cómo gime! / ¡Más ay, cómo suena / el remo a que nos condena») o con la manipulación de conocidas letrillas juveniles: «Si en todo lo qu'hago / soy desgraciada, / ¿qué queréis qu'haga?»» convertida en «¿Qué queréis caga, / mujer, si en todo lo cago / dicen que no cago nada?»; a famosas jácaras de Quevedo («Zampuzado en un banasto»); a pasajes de La vida es sueño con sesgo cómico («Clarín que rompe al albor / no suena mejor»); al celebérrimo estribillo de $E l$ caballero de Olmedo ("Que de noche le mataron / al caballero, / a la gala de Medina, I la flor de Olmedo»), cantado y zapateado; o a cantarcillos anónimos («Que no me las ame nadie»). Si bien este empleo de la lírica popular viene determinado sobre todo por alguna necesidad dramática, su inclusión en escenas con canto y baile suele apuntar hacia algún tipo de enseñanza.

La burla entremesil, en su expresión lingüística, se asocia con la parodia, al servicio del deleite o del juego ocurrente. Lo que Lope de Vega llamaba «bajeza de estilo» en su Arte Nuevo, por ser los entremeses acción de gente plebeya (vv. 72-76). De la comicidad verbal nace el lenguaje avulgarado, popular, incorrecto a veces, bronco, o sus registros particulares, en consonancia con el origen social, particularmente eficaz en la captación de esa atmósfera a medio camino entre el realismo, el costumbrismo y la caricatura.

Un caso prototípico sería el de los alcaldes villanos, unos auténticos paletos que no saben hablar; su esquizofrenia lingüística va acompañada de un sinnúmero de prevaricaciones con el objeto de provocar la hilaridad del público: asimilación de infinitivos, metátesis, formas verbales antiguas, confusión de fonemas o de vocalismo átono... Todo un subgénero en el teatro breve: «josticia, aquí del Rey! [...] No acierto a requebrar a mi querida. / Sopradme por detrás, por vuestra vida [...] Mojer, bien podéis habrar...» (La Mariona).

Al margen del alcalde, la parodia también se extiende al habla de minorías étnicas, extranjeros, vendedores ambulantes, a las hablas dialectales peninsulares o incluso al código amoroso y marginal. Esta comicidad verbal se define, en general, por sus vulgarismos, deformaciones, por sus formas verbales anticuadas, jergas o latines estrafalarios, pullas, juramentos, amenazas... En El francés el protagonista, que debería expresarse en la lengua gala, lo hace en una jerga difícil de discernir, plena de disparates con un único fin desconcertante: «Ricadea e mulo de trifalte longitudo», lo que lleva a sus interlocutores expresiones de extrañeza: «¿Qué lengua es esta, hermana?». La manipulación de las diferentes lenguas y las dificultades de su traducción son elementos caracterizadores siempre en complicidad con el público.

Estilo dinámico, pues, a veces frenético, al servicio del hiperbolismo lingüístico. Uno de los recursos más fértiles brota de la dilogía, en comunión con el chiste fácil, pero

6 Se cita por la edición de las Letrillas de Robert Jammes, 1981, XXVI. 
también del calambur, los equívocos... y, en otra esfera, del lenguaje paremiológico y del folclore ya mencionado.

La «bajeza de estilo» apuntada más arriba va asociada con la extracción social de los personajes y su lenguaje callejero. Entre las expresiones lingüísticas destaca, como no podía ser de otra manera, el lenguaje pullístico, a modo de pequeños debates violentos entre contendientes, en un escenario repleto de gritos e insultos recurrentes. Aunque los duelos de palabras son muy variados, sobresalen en los entremeses canceristas dos: el de los vejetes malhumorados y desconfiados con sus criados y el de las disputas conyugales. La gran fuerza expresiva de estos cañonazos lingüísticos en forma de maldiciones, deprecaciones, amenazas, juramentos, exclamaciones... más el lenguaje avulgarado, exagerado, conforman otra de las señas de identidad del género. En este combate, se pueden apreciar varias modalidades, que van desde el insulto ( «iSois un puerco!») a la frase ingeniosa ( $i$ Vos, limpia de vergüenza!»), al calificativo («Sois un pesado»), al antónimo («Vos, una ligera»), a una frase hecha («Sois hombre de la muerte») o a la dilogía («Vos, mujer de la vida»).

Estos y otros ejemplos recuerdan constantemente cuán lejos se situaban estas obrillas de las representaciones realistas o costumbristas, de donde procedían argumental y temáticamente, porque lo que en verdad se veía en el tablado más que vida era teatro. La estilización caricaturesca los alejaba de esa óptica.

Música y baile cantado es otro recurso fertilísimo. El espectáculo teatral en su conjunto tenía una dimensión musical o bailable considerable, y las piezas breves encajaban como mecanismo de relojería en esa dimensión lúdica. En el $75 \%$ de los entremeses de esta colección se desarrollan secuencias musicales. Donde más brilla es, obviamente, en los remates finales, en esa especie de final feliz despreocupado ajeno a las cuitas iniciales. La forma métrica favorita es la seguidilla, tan adecuada por temática como por su fácil adaptación al canto y al baile, a modo de consejo, epílogo o moraleja, como en este estribillo misógino: «Hoy se ha vengado a su salvo / de amor un hombre de bien. / Albricias hay quien engañe / las mujeres una vez». Enlazando así palabra, música y baile.

Las intercalaciones musicales en el transcurso de la acción también son comunes, integrándose el fragmento en la secuencia métrica, normalmente en romance a diferencia de los finales, aunque también se pueden introducir formas métricas extrañas si se trata de algún conocido estribillo. Tal es el caso del baile cantado del Lanturulú en Las lenguas. El caso de este entremés es paradigmático de los entremeses de revista. Un alcalde va a Madrid a buscar una compañía de baile para las fiestas de su pueblo, y en su deambular van apareciendo diferentes formas como la pavana, las folías, el caballero, el villano o canciones populares gallegas, entre, se supone, la algarabía del público. No obstante estos apuntes, no debe confundir estas regocijadas intromisiones con el subgénero del entremés cantado o del baile entremesado, técnica con la que guarda cierto parentesco.

Consta la selección con una media de 231 versos por pieza, proporción habitual en el género, repartidos casi por igual entre silvas y romances, a diferencia de Quiñones o Moreto más propensos al romance (Lobato 1991: 120 y 2003: 184-185). En su relación 
con su morfología, la silva es la preferida para presentar a los personajes y para abrir el argumento a partir de un punto álgido que atrape de inmediato al espectador. Situación esta que se manifiesta entre los cien primeros versos como media. El romance, por su ductilidad, tiende a ser el soporte del desarrollo de la acción con sus largas tiradas. La seguidilla, la tercera en importancia, es la reservada para los finales cantados y para el triunfo del ingenio por encima de cualquier otra consideración. Con un balance favorable a los metros cortos frente al endecasílabo (61 \% frente a $39 \%$ ). La combinación de ambas medidas en las silvas junto al romance conforma la arquitectura de todas estas obrillas.

\section{La comicidad}

El ingrediente vital de todo entremés que se precie es la comicidad, la burla, entretenimiento sin más aditivos a partir de la materia ridícula. Y esta comicidad debe radicar también en la turpitudo et deformitas ciceroniana, pasada por el tamiz de la tradición carnavalesca. Y para ello es necesario subrayar, en primer lugar, el papel tan crucial que suponía la técnica del actor áureo, quien a través de sus recursos paralingüísticos o kinésicos era, en realidad, el único que podía conquistar al público. Lo cual, en la práctica, suponía un doble esfuerzo, a pesar de su conocimiento sobre unos arquetipos fuertemente codificados. Los entremeses de Cáncer, al igual que los de otros compañeros, sabían explotar bien esa baza. Los golosos de Benavente es particularmente ilustrativa en esta dirección. Averiguar la astucia de unos criados glotones por ver cómo son capaces de desembarazarse de sus manos oprimidas en el transporte de unas apetitosas golosinas, misión encargada por un vejete desconfiado, quien termina a lomos de uno de sus criados y aporreado, nos remite al dinamismo escénico característico de estas piezas, pero también al contorsionismo de unos intérpretes que no necesitan de diálogo para hacer reír. El ingrediente motriz acerca este teatro más al ámbito carnavalesco o circense que al realista o costumbrista del que procede. Las persecuciones, disfraces, golpes, bailes, maquillajes... incluso la onomástica burlesca (Palomino, Mortero, Maridura...), en otro nivel, casi siempre asociada a cualidades risibles o a chanzas, inciden en esa misma dirección. Esta expresión visual no suele venir indicada en las acotaciones del texto, es un trabajo del actor o del moderno filólogo su interpretación.

La burla o el engaño de unos contra otros por encima de todo. Ese es el ingrediente diferencial del entremés frente a otros géneros breves. Esta puede estar motivada por diferentes factores, pero nunca ha de ser violenta o, al menos, así deben sentirla los espectadores. Sus tres propósitos principales son obtener un provecho material o pecuniario de una acción previamente urdida, ocupar el ocio a costa de algún ingenuo o simple o tener como centro el trasiego amoroso y sus complicaciones. A la hora de materializar las intenciones cobran relieve ciertas industrias como la del disfraz, la más importante, y la de objetos con ciertas propiedades mágicas o sobrenaturales a propósito para los incautos.

La técnica del disfraz es especialmente recurrente como vehículo privilegiado en las diferentes trazas, por sus resultados inmediatos en escena. Dado el carácter aplebeyado de los protagonistas, es habitual que estos lo utilicen en su estrategia para hacerse pasar 
por personajes de alta alcurnia, como en el Entremés del Sí, donde unos pícaros lo utilizan para robar en una tienda; pero también como estrategia para cortejar a una dama celosamente guardada por su padre, como el caso del sacristán enamorado disfrazado de gigante de la villa (El gigante); o el de un barbero vestido de convidado de piedra para cobrarse una cena (Juan Ranilla) o el más estrafalario de Juan Rana mujer, donde una esposa encerrada hace creer a su marido que es hombre y él mujer para así poder salir. Los casos de travestismo eran muy aplaudidos por el público.

Todo lo cual daría paso a una tipología ${ }^{7}$ que varía en función de la importancia del ingrediente burlesco. Si lo que predomina es la acción, nos encontraríamos con lo que se ha llamado entremeses de engaño y burlas; si lo es la descripción costumbrista, entonces tendríamos entremeses de acción y ambiente; y si el ingrediente principal es el desfile de una serie de personajes ridículos, entonces daríamos con el entremés de figuras. De todo encontramos en los entretenimientos de Cáncer, siendo el primero de los casos el más común, también el más usual en el género.

Este potencial lúdico de extravagancias poco decorosas desemboca en una literatura de burlas, en parte de una comicidad convencionalizada, pero que gusta poner al descubierto un conjunto de debilidades humanas, vicios, necedades, ambiciones, miedos, miserias... que el autor sabe acondicionar a su contexto sociocultural y literario siempre dentro de unos espacios físicos con valor simbólico, cargados de significación, pero de procedencia urbana, sin alusiones topográficas. Y ello desde los dos bandos, tanto el de los burladores como el de los burlados. ¿Qué nos encontramos entonces? ¿Mera diversión o acerada crítica en este reino pleno de «vacaciones morales» como lo denominaba E. Asensio (1971: 35)? De todo hay en las parodias: de la celebración del ingenio y la chanza a la crítica despiadada de las miserias humanas, del disparate más absurdo a la reflexión moral, siempre sin olvidar que, por encima de todo, prima la diversión, no los mensajes profundos.

Entre el elenco de personajes destacan sobremanera tres emparejamientos con sus respectivos duelos y rasgos ciertamente convencionalizados para que el público pudiera identificarlos rápidamente: el del alcalde y el escribano, al modo de los modernos payasos bobos y agudos, respectivamente; el de hombre-mujer, el más delirante de todos, con sus acostumbradas cargas misóginas y violentas; y el del vejete y criado o gracioso, también de cariz agresivo. La asociación de estas dos últimas figuras viene determinada porque reproducen las estructuras de poder dominantes que se ponen en tela de juicio. La diversión con esta pareja está asegurada: maltrato, insultos, vejaciones, persecuciones, aporreamientos..., es decir, aquello que más se espera de un entremés pleno de acción. Personajes siempre malhumorados y desconfiados, los vejetes de Cáncer gustan de emplear imprecaciones, improperios o maldiciones varias de forma habitual: «iMatarete, vive el cielo!».

En la asociación entre hombres y mujeres, la figura principal es la femenina, en torno a la cual suele girar el argumento. Atrapados en un conflicto que no saben re-

7 Son varios los investigadores que se han dedicado al asunto, desde los fundacionales de los maestros E. Asensio (1971: 18-19) y H.E. Bergman (1970: 13) hasta los más recientes de Ma Luisa Lobato (2003: 44-59) y, sobre todo, Javier Huerta, en varios de sus estudios (1995: 52-66). 
solver, los galanes o maridos no hacen más que quejarse y maldecir a sus damas, pero su actitud es, contrariamente, pasiva. Débiles de carácter son incapaces de afrontar la situación. En el caso de los matrimonios, con sus relaciones inarmónicas, las riñas y peleas están servidas en un ambiente donde no tiene cabida el amor. Fuera del ámbito de la pareja, la mujer adquiere un papel dominante y muestra su superioridad ante el hombre, burlándose casi siempre de él.

El gracioso es probablemente el más prototípico de todos los personajes de estos juguetes cómicos y el más esperado por el bullanguero público. Como evolución o heredero directo del bufón medieval (García Lorenzo 2005), se presenta enfundando diferentes máscaras, parodiando a sus émulos de la Comedia: como crédulo alcalde pueblerino analfabeto, criado ingenuo o cómplice más o menos ingenioso. Su nota más destacable es su candidez, circunstancia que advierten de inmediato sus compañeros de reparto, pues es ideal para sus trazas embaucadoras. Necesario recordar aquí la famosa máscara de Juan Rana, en su papel habitual de bobo. El de alcalde villanesco, todo un subgénero del teatro breve desde que Cervantes marcara sus tipos en La elección de los alcaldes de Daganzo, es en sí mismo una parodia de los alcaldes serios de la Comedia (Pedro Crespo), quien con su justicia arbitraria, su simpleza y otras taras morales, provocaba siempre las delicias del público.

Por último, la celebración del apetito, el hurto y la traza embaucadora, los ejes principales de los entremeses de acción, tiene en los finales musicales, su ingrediente sancionador, pues garantiza el triunfo de la diversión por encima de todas las cosas. Y eso es lo que pretendía Jerónimo de Cáncer, divertir haciendo gala de su ingenio poético.

\section{BIBLIOGRAFÍA}

ACADEMIA ESPAÑOLA (1874): Catálogo de los escritores que pueden servir de autoridad en el uso de los vocablos y de las frases de la lengua castellana. Madrid: Imprenta de Pedro Abienzo.

ARELLANO, Ignacio (ed.) (2005): Teatro breve (loas y entremeses) del Siglo de Oro. Barcelona: Debolsillo.

ASENSIO, Eugenio (1971): Itinerario del entremés. Desde Lope de Rueda a Quiñones de Benavente con cinco entremeses inéditos de D. Francisco de Quevedo. Madrid: Gredos.

BERGMAN, H.E. (ed.) (1970): Ramillete de entremeses y bailes nuevamente recogidos de los antiguos poetas de España. Siglo XVII. Madrid: Castalia.

BUENDÍA, Felicidad (ed.) (1965): Antología del entremés (Desde Lope de Rueda hasta Antonio de Zamora). Siglos XVI y XVII. Madrid: Aguilar.

CÁNCER Y VELASCO, Jerónimo (1691): “Entremés de Las lenguas”, Floresta de entremeses y rasgos del ocio, a diferentes asumptos, de bailes y mojigangas. Escritos por las mejores plumas de nuestra España. Madrid: Antonio de Zafra, pp. 36-45.

(2005): Obras varias, ed. Rus Solera López. Zaragoza: Larumbe. 
(2007): Poesía completa, ed. crítica de Juan C. González Maya. Madrid: Fundación Universitaria Española.

CARREÑO, Antonio (ed.) (1998): Arte Nuevo de hacer comedias en este tiempo, en Lope de Vega. Rimas humanas y otros versos. Barcelona: Crítica, 545-605.

COTARELO Y MORI, Emilio (1911): Colección de entremeses, loas, bailes, jácaras y mojigangas. Madrid: Bailly-Baillière (NBAE 17-18). Ed. facsímil de José L. Suárez y Abraham Madroñal (2000). Granada: Universidad.

ESPINOSA, Aurelio M. (2009): Cuentos populares recogidos de la tradición oral de España, introducción y revisión de Luis Díaz Viana y Susana Asensio Llamas. Madrid: CSIC [1923].

FARRÉ VIDAL, Judith (coord.) (2016): Antonio de Solís. Teatro breve. New York: IDEA.

GARCÍA LORENZO, Luciano (2005): La construcción de un personaje: el gracioso. Madrid: Fundamentos.

GARCÍA VALDÉS, Celsa Carmen (ed.) (1985): Antología del entremés barroco. Barcelona: Plaza y Janés.

GÓNGORA, Luis de (1981). Letrillas, ed. Robert Jammes. Madrid: Castalia.

GONZÁLEZ CAÑAL, Rafael (2013): «Los cuentos en el teatro de Rojas Zorrilla», en Pictavia Áurea. Actas del IX Congreso de la Asociación Internacional del Siglo de Oro, ed. Alain Bègue y Emma Herrán. Toulouse: Presses Universitaires du Midi, 861-870.

GONZÁLEZ MAYA, Juan Carlos (ed.) (2020): Jerónimo de Cáncer. Doce entremeses nuevos. Madrid / Frankfurt: Iberoamericana / Vervuert.

(ed.) (2012): Entremeses Nuevos (1643). Newark Delaware: Juan de la Cuesta.

HUERTA CALVO, Javier (1995): El nuevo mundo de la risa. Estudios sobre el teatro breve y la comicidad en los Siglos de Oro. Palma de Mallorca: José J. Olañeta. (ed.) (1999): Antología del teatro breve español del siglo XVII. Madrid: Biblioteca Nueva.

JAMMES, Robert (ed.) (1981): Luis de Góngora. Letrillas. Madrid: Castalia.

LOBATO, M ${ }^{a}$ Luisa (1991): «Tres calas en la métrica del teatro breve español del Siglo de Oro: Quiñones de Benavente, Calderón y Moreto», en Homenaje a Hans Flasche. Stuttgart: Franz Steiner Verlag.

MADROÑAL DURÁN, Abraham (2013): «De nuevo sobre la autoría de Los refranes del viejo celoso, entremés atribuido a Quevedo». La Perinola, 17, pp. 155-177.

SÁEZ RAPOSO, Francisco (ed.) (2005): Juan Rana y el teatro cómico breve. Madrid: Fundación Universitaria Española.

SOLERA LÓPEZ, Rus (ed.) (2005): Jerónimo de Cáncer y Velasco. Obras varias. Zaragoza: Larumbe.

TARAVACCI, Pietro (2008): «Cáncer», en Historia del teatro breve en España, dir. Javier Huerta Calvo. Madrid / Frankfurt: Iberoamericana / Vervuert, pp. 315343. 
VALBUENA PRAT, Ángel (1937): Historia de la literatura española. Tomo II. Barcelona: Gustavo Gili.

VEGA, Lope de (1998): Arte Nuevo de hacer comedias en este tiempo, en Rimas humanas y otros versos, ed. Antonio Carreño. Barcelona: Crítica, pp. 545-605.

VÉLEZ SAINZ, Julio (2017): «El rey planeta». Suerte de una divisa en el entramado encomiástico en torno a Felipe IV. Madrid / Frankfurt: Iberoamericana / Vervuert.

\section{PERFIL ACADÉMICO Y PROFESIONAL}

Profesor de la Universidad de las Islas Baleares especialista en estudios y ediciones críticas de textos del Siglo de Oro español. Ha publicado ediciones críticas de poesía (Poesía completa de Jerónimo de Cáncer), prosa (Bartolomé Jiménez Patón. Discursos (de calamidades, cruces y herejes) y teatro (Entremeses nuevos (1643) y Jerónimo de Cáncer. Doce entremeses nuevos); además de artículos de revista (Revista de Literatura, Anuario de Historia de la Iglesia, Hispania Sacra, Bulletin Hispanique...) y comunicaciones en diversos congresos nacionales e internacionales. Es miembro de la Asociación Internacional del Siglo de Oro (AISO) y de la Asociación Internacional de Hispanistas (AIH).

Fecha de recepción: 11-03-2021

Fecha de aceptación: 16-04-2021 